\title{
PENDAMPINGAN METODE MUSĀBAQAH BIȚĀQAH MUKHTALITTUL KALIMAH DALAM PEMBELAJARAN BAHASA ARAB DI PONDOK PESANTREN DARUSY SYAHADAH BOYOLALI
}

\author{
Nurul Latifatul Inayati' ${ }^{1}$, Umi Nur Kasanah ${ }^{2}$, Kusnul Khotimah ${ }^{3}$ \\ Afiliasi Pendidikan Agama Islam, Universitas Muhammadiyah Surakarta1,2,3 \\ E-mail: nl122@ums.ac.id1, Ummi.nur.hasan@gmail.com², azkaadzkiya188@gmail.com³
}

Article History:
Received: $16-02-2021$
Revised: $19-02-2021$
Accepted: 21-02-2021

Keywords: Arabic; Musābaqah
Bițāqah Mukhtalițul Kalimah
Method $\quad$ (MBMK; Active
Learning.

Kata Kunci : Bahasa Arab; Metode Musābaqah Bițāqah Mukhtalițul Kalimah (MBMK); Active Learning.

\begin{abstract}
Learning strategies/methods are very important in learning. Errors in the selection of strategies/learning methods can be a barrier to the course of teaching and learning activities (KBM). Arabic is one of the subjects that is highly emphasized in Darusy Syahadah Islamic boarding school. The ability of the Arabic language for a santri is like a weapon that they will use in battle to search for and explore the Islamic sciences. However, in his journey there were several problems encountered in learning Arabic, including the emergence of drowsiness and boredom that befell students while attending Arabic learning. With these problems, it is necessary to have community service activities in order to create a more creative and attractive learning atmosphere for students. The purpose of this community service activity is to provide assistance in the application of the Musābaqah Bițāqah Mukhtalițul Kalimah method in learning Arabic. The implementation method in this community service activity includes four stages, namely the planning stage, the implementation phase, the observation and evaluation stage, and finally the reflection phase. With the application of the Musābaqah Bițāqah Mukhtalițul Kalimah method, it is proven that it can increase the activeness and enthusiasm of student learning which impacts on increasing student learning outcomes. So the development of the Musābaqah Bițāqah Mukhtalițul Kalimah method as well as other active learning methods is very necessary in order to increase student interest in learning.
\end{abstract}

Abstrak: Strategi/metode pembelajaran merupakan hal yang sangat penting dalam sebuah pembelajaran. Kesalahan dalam pememilihan strategi/metode pembelajaran dapat menjadi penghambat jalannya kegiatan belajar mengajar (KBM). Bahasa Arab merupakan salah satu mata pelajaran yang sangat ditekankan di pondok pesantren Darusy Syahadah. Kemampuan bahasa Arab bagi seorang santri ibarat sebuah senjata yang akan mereka gunakan dalam pertempuran mencari dan mendalami ilmu-ilmu syar'i. Namun dalam perjalanannya ditemukan beberapa problematika dalam pembelajaran bahasa Arab, diantaranya yaitu munculnya rasa kantuk dan bosan yang menimpa siswa saat mengikuti pembelajaran bahasa Arab. Dengan persoalan tersebut maka perlu adanya kegiatan pengabdian masyarakat ini guna menciptakan suasana belajar yang lebih kreatif dan menarik bagi siswa. Tujuan diadakannya kegiatan pengabdian masyarakat ini ialah untuk melakukan pendampingan dalam pengaplikasian metode Musābaqah Bițāqah Mukhtalițul Kalimah dalam pembelajaran bahasa Arab. Metode pelaksanaan pada kegiatan pengabdian masyarakat ini meliputi empat tahab, yaitu tahap perencanaan, tahap pelaksanaan, tahap observasi dan evaluasi, dan terakhir tahap refleksi. Dengan penerapan metode Musābaqah Bițāqah Mukhtalițul Kalimah terbukti dapat meningkatkan keaktifan dan semangat belajar siswa yang berimbas pada meningkatnya hasil belajar siswa. Maka pengembangan pada metode Musābaqah Bițāqah Mukhtalițul Kalimah maupun metode pembelajaran active learning lainnya sangat diperlukan agar dapat meningkatkan minat belajar siswa. 


\section{Pendahuluan}

Bahasa merupakan sarana komunikasi yang dipergunakan seseorang untuk menyampaikan isi pikiran dan hatinya kepada lawan bicaranya. Media terpenting dalam sebuah interaksi antar manusia adalah bahasa. Dan salah satu bahasa komunikasi ialah bahasa Arab. Bahasa Arab disematkan sebagai bahasa agama karena 2 sumber pokok pedoman umat Islam yaitu Al-Qur'an dan hadits-hadits Rasulullah berbahasa Arab[1]. Dari hasil wawancara dengan direktur pondok pesantren Darusy Syahadah pada hari Selasa, 05 November 2019 pukul 16.00 didapatkan data bahwa, bahasa Arab merupakan mata pelajaran yang sangat ditekankan di pondok pesantren Darusy Syahadah. Bahasa Arab ibarat pisau bagi seorang santri. Semakin tajam pisau, maka semakin mudah digunakan untuk memotong sesuatu. Begitu pula semakin tinggi kemampuan bahasa Arab yang dimiliki seorang santri, maka semakin banyak pula ilmuilmu syari'at yang dapat ia kumpulkan.

Namun dalam perjalanannya dalam pembelajaran bahasa Arab ditemukan beberapa problematika atau kendala. Thomas menuturkan bahwa terdapat beberapa faktor yang mempengaruhi turunnya semangat siswa dalam mempelajari bahasa Arab. Pertama, faktor eksternal, diantaranya ialah kurangnya ketepatan dalam pemilihan materi dan metodologi pembelajaran, atau strategi yang digunakan kurang bervariatif. Sedangkan faktor internal diantaranya ialah sikap negatif siswa terhadap bahasa Arab, atau rendahnya pengalaman belajar siswa di jenjang sebelumnya serta lemahnya kemampuan dasar yang dimiliki siswa sebelumnya[2]. Penghambat/kendala lainnya yaitu terkait sosiokultural di Indonesia berbeda dengan di Arab, hal ini juga menjadi problem tersendiri dalam belajar bahasa Arab[3].

Dari hasil wawancara dengan guru mata pelajaran bahasa Arab kelas 1 KMA C pada hari Rabu, 13 November 2019 pukul 11.00 diketahui bahwa terdapat persoalan yang perlu diperhatikan terkait metodologis dalam pembelajaran bahasa Arab. Beberapa siswa kelas $1 \mathrm{KMA} C$ dilanda rasa kantuk dan bosan saat pembelajaran bahasa Arab. Ketika suasana kelas mulai hening, maka guru mapel berusaha menghidupkan kembali suasana kelas dengan berbagai strategi/teknik. Diantaranya ialah dengan mengajak para santri untuk menyanyikan kaidah-kaidah nahwu yang sudah mereka hafal, mengerjakan soal di papan tulis, dan lain sebagainya. Namun cara ini dirasa belum mampu dijadikan satu-satunya solusi.

Dalam pencapaian tujuan pembelajaran maka dibutuhkan metode yang tepat. Metode ibarat pelicin jalan pengajaran menuju tujuan yang diinginkan. Pemakaian metode yang tidak tepat akan menjadi penghambat dalam proses pencapaian tujuan pembelajaran[4]. Berkenaan dengan hal ini, maka peneliti bermaksud ingin menciptakan pembelajaran bahasa Arab yang lebih bervariatif dengan pendekatan active learning melalui permainan kosa kata. Dengan ini harapannya mampu 
Jurnal Pengabdian Masyarakat Nusantara

Vol. 1, No. 1, Februari, 2021, hal : 18-30, E-ISSN : 2775-734X DOI: https://doi.org/10.35870/jpmn.v1i1.263

meminimaliser rasa kantuk dan bosan pada siswa sehingga pembelajaran bisa berjalan lebih efektif dan akhirnya berimbas pada meningkatnya kemampuan bahasa Arab yang dimiliki siswa.

Hamalik dalam Afifatu Rohmawati mengungkapkan bahwa pembelajaran dikatakan efektif apabila pembelajaran tersebut memberikan kesempatan kepada peserta didik untuk melakukan aktivitas sebebas-bebasnya dan belajar secara mandiri[5]. Adapun Hidayat dalam Muhammad Irwan Padli Nasution, mengartikan efektivitas/efektif sebagai suatu ukuran yang menyatakan seberapa jauh target yang telah tercapai[6]. Dari penjelasan di atas maka dapat ditarik kesimpulan bahwa metode pembelajaran dapat dikatakan efektif apabila metode pembelajaran tersebut dapat membantu memudahkan/ mengarahkan siswa dalam mencapai tujuan pembelajaran yang telah ditetapkan guru.

Pada strategi active learning (belajar aktif) peserta didik berperan sebagai inti dalam kegiatan belajar mengajar. Mereka berperan sebagai subjek dan objek dalam kegiatan pembelajaran[7]. Mereka memanfaatkan kemampuan otak yang mereka miliki untuk memecahkan permasalahan dan menemukan konsep yang benar terkait materi yang mereka pelajari[8]. Pada dasarnya tujuan dari active learning ialah untuk menciptakan suasana kelas yang menyenangkan sehingga tercapainya hasil belajar yang memuaskan[9]. Suasana belajar aktif akan tercipta jika terdapat keaktifan baik dari pihak guru maupun peserta didiknya[10].

Metode Musābaqah Bițāqah Mukhtalițul Kalimah (MBMK) adalah suatu strategi pembelajaran yang pengaplikasiannya memanfaatkan media kartu. Adapun teknisnya yaitu menyusun sebuah kalimat yang benar sesuai kaidah bahasa Arab dari kata-kata yang telah diacak dalam durasi waktu tertentu[11]. Melalui metode ini siswa diajak untuk melatih daya pikir yang mereka miliki agar lebih aktif dan kreatif. Karena dalam pembelajaran dengan strategi/metode ini, siswa dituntut untuk berfikir keras agar dapat memecahkan persoalan atau menemukan jawaban yang tepat[12].

Dari hasil observasi tahap awal dan wawancara, permasalahan yang ditemui adalah sebagai berikut: a) Pembelajaran masih terpusat pada guru. b) Metode pembelajaran yang digunakan guru belum bervariatif. Metode yang digunakan lebih pada pemberian informasi. c) Beberapa siswa terkadang terlihat tidak fokus pada pembelajaran. Beberapa ada yang berbicara/ngobrol sendiri, mengantuk, kurang semangat dalam belajar, dan lain-lain. d) Beberapa siswa terlihat masih malu-malu atau takut untuk aktif di kelas, baik untuk menyampaikan pendapat ataupun sekedar bertanya kepada guru terkait materi yang belum dipahami.

Dari permasalahan yang ada, maka peneliti berinisiatif untuk melakukan inovasi untuk meningkatkan keaktifan siswa dalam pembelajaran bahasa Arab sehingga berdampak pada meningkatnya semangat belajar siswa. Tujuan diadakannya kegiatan pengabdian masyarakat ini ialah untuk melakukan pendampingan dalam 
Jurnal Pengabdian Masyarakat Nusantara

pengaplikasian metode Musābaqah Bițāqah Mukhtalițul Kalimah dalam pembelajaran bahasa Arab kelas 1 KMA C pondok pesantren Darusy Syahadah Boyolali.

\section{Metode}

Metode pelaksanaan kegiatan Pengabdian Masyarakat dilakukan dengan memberikan pendampingan dalam peningkatan keaktifan dan kemampuan bahasa Arab siswa melalui Metode Musābaqah Bițāqah Mukhtalițul Kalimah di pondok pesantren "Darusy Syahadah" Desa Kedunglengkong, Kecamatan Simo, Kabupaten Boyolali, yaitu:

1. Perencanaan

a. Tim pengabdian masyarakat melakukan observasi langsung ke pondok pesantren Darusy Syahadah Boyolali untuk mengidentifikasi, menganalisis permasalahan, kebutuhan dan potensi yang ada.

b. Tim pengabdian masyarakat mengadakan pertemuan terkait pembekalan mengenai tujuan, rancangan mekanisme peaksanaan pengabdian masyarakat dan penyusunan program pengabdian masyarakat terkait pengiplementasian metode Musābaqah Bițāqah Mukhtalițul Kalimah untuk meningkatkan keaktifan dan kemampuan bahasa Arab siswa kelas 1 KMA C pondok pesantren Darusy Syahadah Boyolali.

c. Tim pengabdian masyarakat mengajukan ijin dan melakukan kontrak waktu pelaksanaan pengabdian masyarakat ke pihak pondok pesantren Darusy Syahadah Boyolali.

2. Tindakan

Tindakan dalam kegiatan Pengabdian Masyarakat ini berupa implementasi program kegiatan pengabdian masyarakat yang diberikan dalam bentuk pendampingan untuk:

a. Meningkatkan keaktifan dan semangat belajar siswa di kelas.

b. Meningkatkan kemampuan bahasa Arab siswa.

c. Mendasain/merancang dan mengimplementasikan media kartu kata berbahasa Arab, panduan penggunaan, tujuan pembelajaran untuk memudahkan guru dan siswa dalam menggunakan permainan kosakata, dan kunci jawaban yang berisi kalimat-kalimat yang sesuai dengan kaidah bahasa Arab.

d. Mengimplementasikan media permainan kosakata dengan cara bermain secara berkelompok dalam sebuah perlombaan untuk melatih ketrampilan menulis bahasa Arab siswa.

Adapun langkah-langkah pengaplikasian metode Musābaqah Biṭāqah Mukhtalițul Kalimah dalam pembelajaran bahasa Arab, sebagai berikut: 


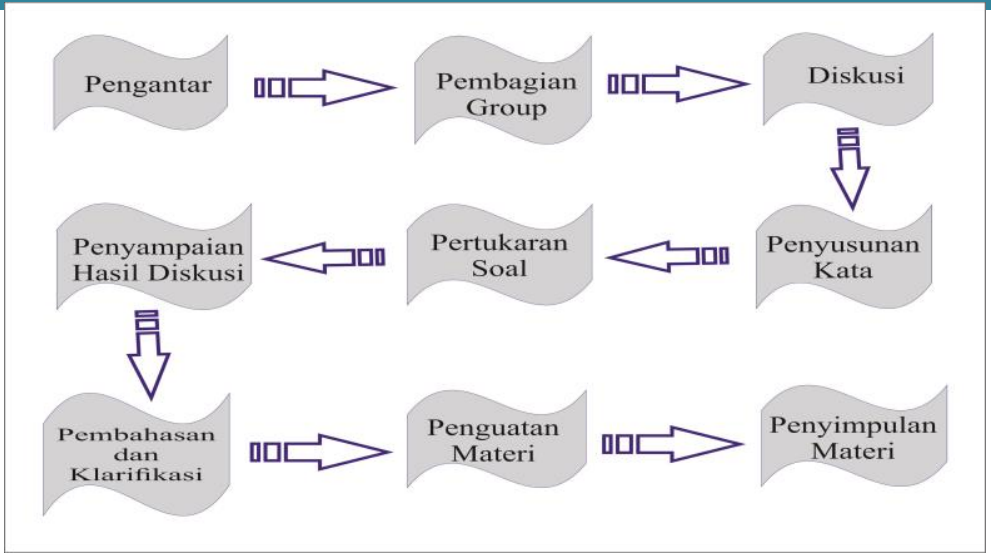

Gambar 1. Bagan alur kegiatan belajar mengajar dengan Metode MBMK

Tabel 1. Langkah-langkah pengaplikasian Metode MBMK

\begin{tabular}{|c|c|c|}
\hline Tahapan & Peserta Didik & Guru \\
\hline Langkah 1 & $\begin{array}{l}\text { Seluruh peserta didik } \\
\text { mendengarkan dengan } \\
\text { seksama arahan dari guru }\end{array}$ & $\begin{array}{l}\text { Guru memberikan pengantar } \\
\text { di awal pembelajaran }\end{array}$ \\
\hline Langkah 2 & $\begin{array}{l}\text { Setiap group memilih salah } \\
\text { satu anggotanya untuk } \\
\text { menjadi ketua group. }\end{array}$ & $\begin{array}{l}\text { Guru membagi peserta didik } \\
\text { menjadi } 8 \text { group. Dilanjutkan } \\
\text { dengan pemberian pengantar } \\
\text { terkait metode yang akan } \\
\text { digunakan }\end{array}$ \\
\hline Langkah 3 & $\begin{array}{l}\text { Seluruh ketua group secara } \\
\text { bersamaan mengambil satu } \\
\text { paket kartu yang berisi } \\
\text { beberapa kosa kata yang } \\
\text { telah disediakan guru. }\end{array}$ & $\begin{array}{l}\text { Guru menyiapkan kartu-kartu } \\
\text { yang telah dibuat. }\end{array}$ \\
\hline Langkah 4 & $\begin{array}{l}\text { Ketua group memberikan } \\
\text { satu paket kartu yang } \\
\text { didapat kepada anggota } \\
\text { groupnya. }\end{array}$ & $\begin{array}{l}\text { Guru memberikan tanda } \\
\text { bahwa waktu perlombaan } \\
\text { telah dimulai. Dan } \\
\text { memberikan durasi waktu } 5 \\
\text { menit untuk setiap putaran. }\end{array}$ \\
\hline Langkah 5 & $\begin{array}{l}\text { Santri membuka paket } \\
\text { kartu kemudian berdiskusi } \\
\text { dengan groupnya untuk } \\
\text { menyusun kalimat yang } \\
\text { benar dan menentukan } \\
\text { i'rabnya. }\end{array}$ & $\begin{array}{l}\text { Guru memantau dan } \\
\text { membantu group yang masih } \\
\text { kebingungan. Masing-masing } \\
\text { soal diberikan estimasi waktu } \\
\text { pengerjaan agar pertukaran } \\
\text { soal bisa teratur. }\end{array}$ \\
\hline Langkah 6 & $\begin{array}{lrr}\text { Santri mengacak } & \text { kembali } \\
\text { kartu-kartu yang } & \text { mereka } \\
\text { dapatkan dan } & \text { siap }\end{array}$ & $\begin{array}{l}\text { Guru memberikan tanda } \\
\text { bahwa waktu sudah habis. }\end{array}$ \\
\hline
\end{tabular}


diberikan ke group lainnya.

Langkah 7 Masing-masing ketua group memberikan paket kartu ke group berikutnya. Putaran kartu searah dengan putaram jarum jam dimulai dari Group A ke B, group B ke $C$, group $C$ ke $D$, group $D$ ke $E$, group $E$ ke $F$, group $F$ ke $G$, group $G$ ke $H$ dan group $\mathrm{H}$ ke $\mathrm{A}$.

Langkah 8 Masing-masing group akan mendapatkan 8 kali putaran paket kartu. Jadi kalimat yang terkumpulkan setiap group ada 8 kalimat.

Langkah 9 Peserta didik menuliskan hasil diskusi pada selembar kertas.

$\begin{aligned} \text { Langkah } 10 & \text { Perwakilan masing-masing } \\ & \text { group menuliskan satu } \\ & \text { jawaban di papan tulis } \\ & \text { kemudian dilanjutkan } \\ & \text { dengan pembahasan secara } \\ & \text { bersama-sama. }\end{aligned}$

Langkah 11 Masing-masing group mengoreksi hasil diskusi milik group lain dan memberikan nilai.
Memantau dan memberikan arahan bagi group yang masih bingung. Guru juga berperan sebagai timekiper.

Guru memantau dan mengkondisikan kelas.

Setelah selesai penulisan, guru memberikan instruksi kepada peserta didik untuk saling tukar menukar hasil pekerjaan mereka.

Guru memberikan apresiasi dan klarifikasi.

Memberikan reward pada group pemenang. Dan pemberian motivasi untuk meningkatkan semangat belajar group lainnya.

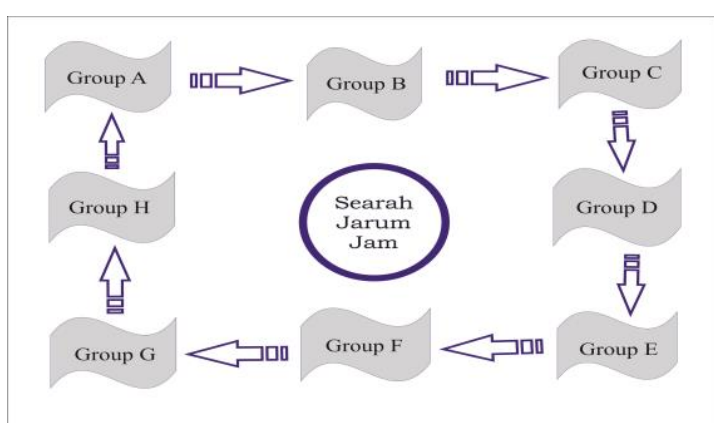

Gambar 2. Bagan alur pertukaran soal 
Jurnal Pengabdian Masyarakat Nusantara

3. Observasi dan evaluasi

Observasi dilakukan terhadap guru dan siswa untuk mengimplemantasikan metode Musābaqah Bițāqah Mukhtalițul Kalimah dalam pembelajaran bahasa Arab. Instrumen yang digunakan berupa catatan lapangan. Beberapa hal yang diobservasi ialah kendala atau kekurangan yang muncul selama proses pengimplemantasian metode Musābaqah Biṭāqah Mukhtalițul Kalimah untuk meningkatkan keaktifan dan kemampuan bahasa Arab siswa kelas 1 KMA C pondok pesantren Darusy Syahadah Boyolali. Evaluasi dilakukan terhadap keluaran yang dihasilkan.

4. Refleksi

Refleksi dilakukan terhadap kegiatan yang telah dilaksanakan. Hal ini dilakukan semata-mata untuk mengetahui kekurangan atau kelebihan terhadap kegiatan pengabdian masyarakat yang telah dilakukan dalam rangka untuk menetapkan rekomendasi terhadap keberlangsungan kegiatan pengabdian masyarakat selanjutnya.

\section{Hasil dan Pembahasan}

Hasil yang dicapai melalui kegiatan pengabdian masyarakat ini dituangkan dalam bentuk hasil kegiatan pada setiap tahap pelaksanaan sebagai berikut:

\section{Perencanaan}

Kegiatan yang telah dilakukan pada tahap perencanaan adalah sebagai berikut:

a. Tim pengabdian masyarakat mengadakan pertemuan untuk membahas mengenai tujuan dan rancangan mekanisme pelaksanaan pengabdian masyarakat sera pertanggungjawaban pada pihak yayasan.

b. Berdasarkan hadil identiikas, hasil analisis masalah yang ada, selanjutnya tim pelaksana melaksanakan program pengabdian masyarakat pada hari Rabu, 26 Februari 2020 di ruang kelas 1 KMA C pondok pesantren Darusy Syahadah Boyolali. Siswa yang megikuti kegiatan ini adalah siswa kelas 1 KMA C dengan jumlah siswa 38.

2. Pelaksanaan Kegiatan

Tindakan dalam kegiatan ini berupa implemantasi program. Tim pelaksana pengabdian masyarakat membagi siswa menjadi 8 kelompok dan masing-masing kelompok memilih ketua kelompok. Tim pelaksana pengabdian masyarakat memberikan arahan, bimbingan dan pendampingan selama perlombaan berlangsung.

Kegiatan yang dilakukan tim pelaksana pengabdian masyarakat dalam implementasi program adalah sebagai berikut:

a. Tim pelaksana pengabdian masyarakat membuat media pembelajaran yaitu media kartu kata berbahasa Arab. 


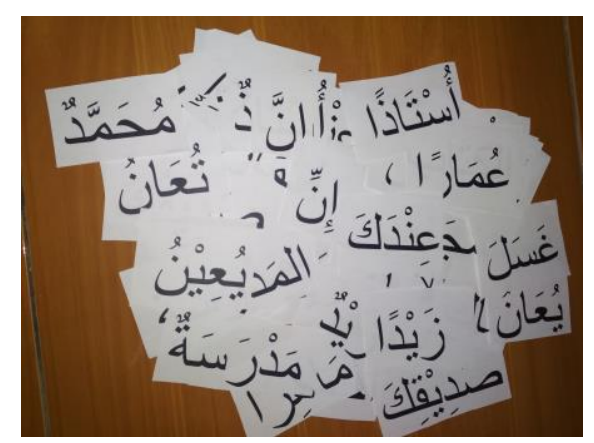

Gambar 3. Media pembelajaran kartu kata

b. Kegiatan awal

Pada kegiatan awal, tim pelaksana pengabdian masyarakat membuka pembelajaran dengan mengucapkan salam dan mengabsen siswa. Selanjutnya mengecek kesiapan siswa sebelum mengikuti pembelajaran. Untuk mengembalikan kefokusan siswa dalam belajar, sebelum memulai pembelajaran guru mengajukan beberapa pertanyaan terlebih dahulu kepada para siswa. Setelah kefokusan siswa kembali,guru menjelaskan kepada siswa terkait tujuan pembelajaran yang akan dicapai siswa setelah mengikuti pembelajaran. Kemudian guru memberikan gambaran besar terkait metode pembelajaran yang hendak digunakan.

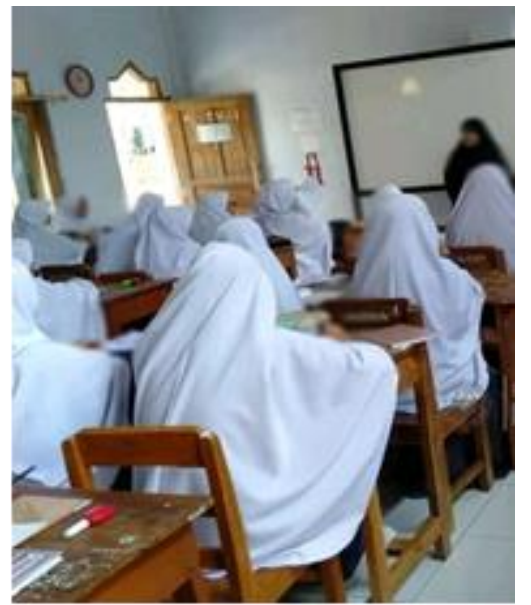

Gambar 4. Kegiatan awal sebelum memasuki kegiatan inti

c. Kegiatan inti

Pada kegiatan inti, sebelum permainan dimulai, tim pelaksana pengabdian masyarakat memberikan sedikit materi kepada siswa. Tim pelaksana pengabdian masyarakat menerangkan tentang pengertian الدمنادى dari segi bahasa dan istilah. Kemudian siswa menanyakan hal-hal yang belum dipahami. Lalu dilanjutkan dengan kegiatan diskusi bersama kelompok masing-masing. Setelah diskusi selesai, maka langkah berikutnya yaitu pembahasan hasil diskusi secara bersama-sama dan dilanjutkan dengan klarifikasi materi oleh guru. Kemudian tim pelaksana pengabdian masyarakat mengumumkan kelompok yang menjadi pemenang. Tim pelaksana pengabdian masyarakat memberikan 
reward kepada semua kelompok dengan besar hadiah yang berbeda sesuai dengan urutan peringkat masing-masing.

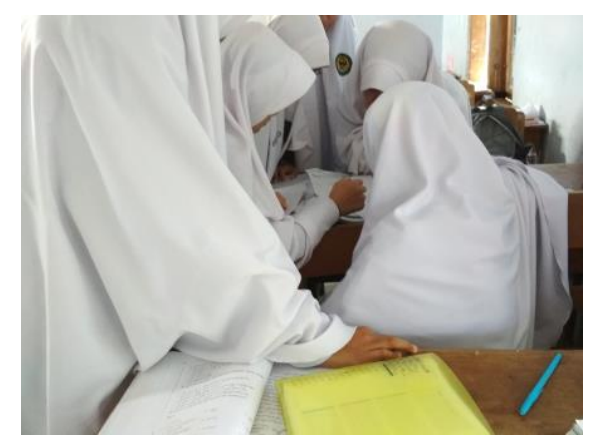

Gambar 5. Kegiatan diskusi siswa

d. Kegiatan akhir

Pada kegiatan akhir, ada beberapa hal yang dilakukan tim pelaksana pengabdian masyarakat. Pertama, guru memberikan evalusi kognitif kepada siswa sebagai sarana untuk penguatan materi. Kedua, guru memberikan tugas kepada siswa untuk membuat contoh kalimat الــنادى. Ketiga, guru memberikan motivasi kepada siswa agar tetap semangat dalam belajar dan menuntut ilmu. Terakhir tim pelaksana pengabdian masyarakat menutup dengan permohonan maaf dan salam.

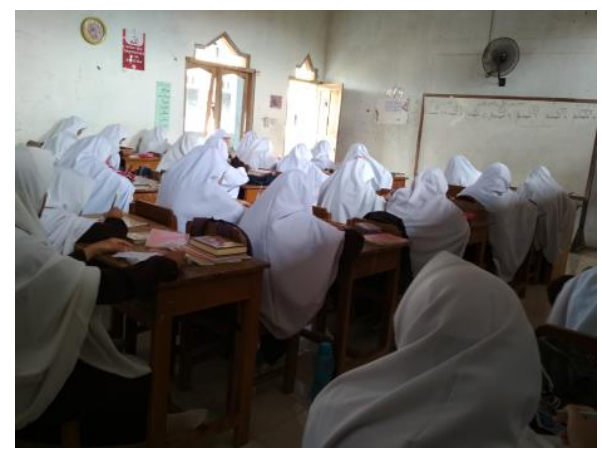

Gambar 6. Kegiatan evaluasi kognitif siswa

3. Observasi dan Evaluasi

Observasi dilakukan sebelum, selama, dan setelah kegiatan pengabdian. Kegiatan pengabdian ini berlangsung lancar meskipun ada sedikit kendala terkait teknis pengaplikasian metode MBMK, akan tetapi permasalahan tersebut bisa teratasi sehingga kegiatan berlangsung dengan baik. Seluruh siswa sangat senang mengikuti kegiatan ini. Hal ini dapat dilihat dari antusisme mereka dalam mengikuti pembelajaran. Mereka terlihat sangat aktif dalam mengikuti perlombaan penyusunan kata, dibuktikan dengan usaha setiap anggota kelompok dalam memecahkan soal yang ada. 


\section{Tabel 2. Data keaktifan siswa}

\begin{tabular}{clc}
\hline No. & \multicolumn{1}{c}{ Kriteria } & $\begin{array}{c}\text { Banyak } \\
\text { santri }\end{array}$ \\
\hline 1. & Sangat Aktif & 20 \\
2. & Aktif & 14 \\
3. & Kurang Aktif & 4 \\
4. & Tidak Aktif & - \\
\hline & Jumlah & $\mathbf{3 8}$ \\
\hline
\end{tabular}

Prosentase Keaktifan Santri $=$

$$
\begin{gathered}
\frac{\text { Banyak Santri aktif }}{\text { Jumlah Santri }} \times 100 \% \quad \frac{34}{38} \times 100 \% \\
=89 \%
\end{gathered}
$$

Tabel 3. Hasil tes evaluasi kognitif

\begin{tabular}{ccccc}
\hline No. & Nilai & $\begin{array}{c}\text { Banyak } \\
\text { Santri }\end{array}$ & Jumlah & Capaian \\
\hline 1. & 50 & 2 & 100 & Sedang \\
2. & 60 & 3 & 180 & Sedang \\
3. & 70 & 7 & 490 & Tinggi \\
4. & 80 & 9 & 720 & Tinggi \\
5. & 90 & 9 & 810 & Sangat Tinggi \\
6. & 100 & 8 & 800 & Sangat Tinggi \\
\hline & Jumlah & $\mathbf{3 7}$ & $\mathbf{2 . 9 6 0}$ & \\
& Rata-rata & & $\mathbf{8 1 , 5}$ & Tinggi \\
\hline
\end{tabular}

Prosentase Ketuntasan Santri $=$

$$
\begin{aligned}
\frac{\text { Banyak Santri lulus KKM }}{\text { Jumlah santri }} \times 100 \% & =\frac{36}{38} \times 100 \% \\
& =95 \%
\end{aligned}
$$

Prosentase keaktifan siswa di kelas menunjukkan angka yang cukup tinggi, yaitu 89\%. Hasil evaluasi kognitif siswa yang diambil usai pembelajaran pun menunjukkan angka prosentase kelulusan yang menggembirakan, yaitu 95\%. Tim pelaksana pengabdian masyarakat memberikan reward atau hadiah kepada seluruh kelompok. Untuk kelompok yang mendapat juara 1, 2 \& 3 mendapatkan hadiah yang lebih besar dibanding kelompok-kelompok lainnya.

4. Refleksi

Hasil refleksi kegiatan ini berlangsung cukup baik. Para siswa menunjukkan keaktifan dan semangat belajar yang tinggi ketika mengikuti pembelajaran. Pembelajaran tidak lagi terpusat pada guru melainkan guru hanya berperan 
sebagai fasilitator dan pembimbing bagi santri. Dari hasil wawancara diketahui bahwa menurut siswa metode MBMK dapat meningkatkan semangat belajar mereka. Alasan yang mereka utarakan bervariatif. Alasan pertama, karena dalam kerja group sesama anggota group bisa saling membantu satu sama lain, santri yang sudah paham mengajari temannya yang belum paham. Kedua, santri merasa tersegarkan dengan adanya game tersebut sehingga mereka semangat dalam mengikuti pembelajaran dan tidak merasa bosan. Ketiga, karena metode MBMK berbeda dengan metode-metode yang biasa dipakai dalam pembelajaran dan dapat meningkatkan keaktifan santri. Keempat, karena dengan metode MBMK maka santri dituntut untuk bisa berfikir dan bekerja cepat. Dan alasan kelima, dengan metode MBMK ini maka santri dapat melatih kekompakan Dalam penerapan metode MBMK ini dibutuhkan maenejemen waktu yang tepat agar pembelajaran bisa berlangsung dengan maksimal. Maka dari itu sangat dibutuhkan perencanaan dan persiapan yang matang. Selain itu, dalam pengaplikasiannya juga dibutuhkan ruang belajar yang luas agar posisi tempat duduk beraturan sehingga perputaran soal dapat berjalan secara teratur dan kondusif. Di tengah-tengah proses pembelajaran bisa diselingi dengan ice breaking agar siswa lebih bisa bersemangat lagi dalam mengikuti pembelajaran.

\section{Kesimpulan dan Saran}

1. Simpulan yang dicapai melalui kegiatan pengabdian masyarakat ini adalah sebagai berikut:

- Meningkatnya keaktifan siswa dalam kelas dan kemampuan bahasa Arab siswa.

- Terciptanya suasana belajar yang lebih kreatif dan menarik.

- Meningkatnya pengetahuan dan pemahaman guru dan siswa terkait pengaplikasian metode Musābaqah Bițāqah Mukhtalițul Kalimah dalam pembelajaran bahasa Arab.

2. Saran yang dapat disampaikan dalam kegiatan pengabdian msasyarakat adalah:

- Diharapkan siswa dapat lebih aktif dalam mengikuti diskusi group dan menjalin hubungan yang baik dengan anggota group dengan saling membantu dan menghargai teman segroup maupun group lain.

- Diharapkan guru mampu menciptakan pembelajaran yang bervariatif dan kreatif secara berkesinambungan guna meningkatkan semangat belajar siswa dengan melalukan inovasi metode-metode pembelajaran active learning dan menerapkannya pada pembelajaran.

- Diharapkan adanya pengembangan pada metode Musābaqah Bițāqah Mukhtalițul Kalimah agar dapat menjadi sebuah metode pembelajaran yang dapat diaplikasikan secara outdoor dan dapat dikolaborasikan dengan metode active learning lainnya. 


\section{Pengakuan/Acknowledgements}

Terselenggaranya kegiatan pengabdian masyarakat ini tidak lepas dari dukungan berbagai pihak. Untuk itu dalam tulisan ini kami mengucapkan terima kasih kepada LPPM UMS, tim dosen dan tim mahasiswa pelaksana pengabdian masyarakat, dan berbagai pihak yang terlibat dari pondok pesantren Darusy Syahadah Boyolali.

\section{Daftar Referensi}

[1] Iswanto R. Pembelajaran Bahasa Arab dengan Pemanfaatan Teknologi. Arab J Bhs Arab. 2017;1(2):139-152.

[2] Islam AMS. Faktor Demotivasi Pembelajaran Bahasa Arab Dalam Persepektif Siswa Madrasah. Arab J Pendidik Bhs Arab. 2015;2(1):1-16.

[3] Hidayat NS. Problematika Pembelajaran Bahasa Arab. J Pemikir Islam. 2012;37(1):82-89.

[4] Samiudin. Peran Metode Untuk Mencapai Tujuan Pembelajaran. J Stud Islam. 2016;11(2):113-131.

[5] Rohmawati A. Efektivitas Pembelajaran Afifatu. J Pendidik Usia Dini. 2015;9(1):1532.

[6] Nasution MIP. Strategi Pembelajaran Efektif Berbasis Mobile Learning Pada Sekolah Dasar. J Iqra'. 2016;10(01):1-14.

[7] Baharun H. Penerapan Pembelajaran Active Learning Untuk Meningkatkan Hasil Belajar Siswa Di Madrasah. J Pendidik Pedagog. 2015;01(01):34-46.

[8] Yaman B. Pelaksanaan Metode Active Learning Dalam Meningkatkan Hasil Belajar Siswa Pada Pembelajaran Pendidikan Agama Islam (Studi Kasus Siswa Kelas X SMKN 9 Surakarta Tahun Pelajaran 2014/2015). Skripsi Fak Agama Islam Univ Muhammadiyah Surakarta. Published online 2015:1-14.

[9] Mentari. Penerapan Model Active Learning Tipe Card Sort Untuk Meningkatkan Aktivitas Dan Hasil Belajar Matematika Siswa Kelas IV SD Negeri 1 Jurang Ubung. Skripsi Fak Kegur dan Ilmu Pendidikan, Univ Lampung. Published online 2016:1100.

[10] Masruroh U. Implementasi Strategi Belajar Aktif (Active Learning) Dalam Pembelajaran Tematik Di MIN Kauman Utara Jombang. Skripsi Fak Ilmu Tarb dan Keguruan, Univ Islam Negeri Maulana Malik Ibrahim. Published online 2017:1209.

[11] Rahmawati L. Penerapan Metode Musabaqah Bithaqah Mukhtalithul Kalimah 'MBMK' untuk Meningkatkan Hasil Belajar Maharah Al - Kitabah Siswa Kelas X D MAN 1 Yogyakarta. Al-Mahara J Pendidik Bhs Arab. 2018;4(2):285-308.

[12] Wahyuningsih S. Pengaruh Strategi Random Text terhadap Hasil Belajar Peserta Didik Pada Mata Pelajaran Al-Qur'an Hadits Kelas IV MI Masyariqul Anwar 4 
Jurnal Pengabdian Masyarakat Nusantara

Vol. 1, No. 1, Februari, 2021, hal : 18-30, E-ISSN : 2775-734X DOI: https://doi.org/10.35870/jpmn.v1i1.263

Sukabumi Bandar Lampung. Skripsi Fak Tarb dan Keguruan, Univ Islam Negeri Raden Intan Lampung. Published online 2018:1-69. 